\title{
EDUCAÇÃO A DISTÂNCIA E FORMAÇÃ̃O CONTINUADA EM CIÊNCIAS: INDICATIVOS PARA CONFIGURAÇÃO DE CURSOS VIA INTERNET
}

\author{
Distance education and the continuous formation in Science: the courses' \\ configuration via internet
}

\author{
Ana Cristina Cristo Vizeu Lima ${ }^{1}$ \\ Cícero Roberto Teixeira Régis ${ }^{2}$
}

\section{RESUMO}

Este artigo trata de uma pesquisa sobre as condições necessárias para a utilização da Educação a Distância Via Internet em ações de Formação Continuada de Professores de Ciências. A investigação teve como objetivo traçar indicativos para uma proposta de uso dessa modalidade de ensino em ações de Formação Continuada de Professores de Ciências no Estado do Pará. A metodologia qualitativa, com base na narrativa, foi usada para interpretação de dados registrados nos perfis/memoriais via internet e nas interações assíncronas (emails e fóruns), e síncronas (chats) colhidos durante os cursos de formação continuada que tiveram como suporte o ambiente virtual de aprendizagem eProinfo/MEC. Os resultados da análise nos remetem à falta de habilidade dos professores de ciências ao uso da necessária interação a distância, e ao preconceito e a desconfiança que formadores e cursistas sutilmente manifestam ao participar de um curso a distância. Os indicativos se referem prioritariamente à preparação de pessoas para ambientação e acolhimento aos professores de ciências cursistas, assim como à atualização metodológica em relação à modalidade a distância para os formadores.

Palavras-chave: Formação de professores de ciências; Educação continuada a distância, Tecnologias de Informação e Comunicação Via Internet.

\begin{abstract}
This article shows a research about the necessary conditions for the use of distance education via internet in actions of continuous formation of Science teachers. The investigation aimed to show indicatives for one proposal for the use of this kind of teaching for Science teachers in the state of Pará. The methodology used was the narrative and it was analysed the data obtained during the formation courses that had as a support the virtual environment

\footnotetext{
${ }^{1}$ Mestre em Educação em Ciências pela Universidade Federal do Pará, Brasil (2009). Atua nas áreas de Ensino de Ciências e Biologia e com a Formação de Professores. cristo@ufpa.br.

${ }^{2}$ Doutor em Geofísica pela Universidade Federal do Pará, Brasil(2000). Professor de Ensino Superior da Universidade Federal do Pará , Brasil.

AMAZÔNIA - Revista de Educação em Ciências e Matemáticas V.6 - n. 11 - jul. 2009/dez. 2009, V. 6 - n. 12 - jan 2010/jun. 2010
} 
eProinfo/MEC. The results shows us the lack of hability of those teachers concerning to the usage of the necessary distance interaction and also the prejudice and not confidence that was manifested by them. The indicatives referred in a priority way to the preparation of those people for the environment, and also the methodological update in relation to distance education for educators.

Keywords: formation of Science teachers; continuous distance education, information and communication technology via internet.

\section{INTRODUÇÃO}

As mudanças que se descortinam com o advento da revolução tecnológica exigem de nós, professores, preparação para um novo tempo que nos habilite a auxiliar os jovens a enfrentarem os desafios que se apresentam nessa sociedade da informação (ALARCÃO, 2006). Os desafios são imensos e os obstáculos parecem maiores ainda: baixos salários, falta de uma proposta de valorização e qualificação profissional, carga horária de trabalho excessiva e consequente dificuldade de acesso a livros e periódicos inviabilizam e desmotivam a busca desse profissional por atualização e formação.

Em se tratando do contexto amazônico, suas peculiaridades trazem especificidades no tratamento da formação desses professores, principalmente, no que diz respeito à superação das tradicionais tarefas de transmitir informações e ultrapassar os limites das distâncias e do tempo. Nas comunidades da Amazônia, o rio não está separado através de uma ponte, ele é parte da vida daqueles homens. O que dificulta sobremaneira o acesso a essas comunidades.

Com esse panorama, vislumbramos o uso da Educação a distância $(\mathrm{EaD})$ via internet, como modalidade capaz de ampliar as oportunidades educacionais, gerando condições que minimizam o problema das distâncias físicas, ao mesmo tempo em que aumenta o atendimento da demanda por melhor qualificação, sempre crescente em nossa realidade regional.

Nesse contexto da Formação de Professores no Estado do Pará, desenvolve-se esta investigação orientada pela pesquisa qualitativa, cujo objetivo é estabelecer indicativos para uma proposta de uso da Educação a Distância aliada às Tecnologias da Informação e Comunicação (EaD Via Internet), como modalidade de ensino para promoção de ações de Formação Continuada aos Professores de Ciências para o Estado do Pará.

A questão que motivou o presente trabalho é a de que fatores se revelam nas interações e participações dos professores em contextos de cursos a distância via internet e que podem servir de indicativos para a elaboração de uma proposta de implementação de cursos de formação continuada em ensino de ciências a distância via internet para o Estado do Pará?

A ideia do uso da modalidade da EAD via internet para a formação de professores de ciências emerge na percepção de oportunidades que surgem no cenário político nacional, com incentivos à democratização da educação no país através dessa modalidade de ensino. Essas oportunidades tornam o momento propício à busca de indicativos no âmbito de cursos à distância a fim de implementá-los com qualidade. 

EDUCAÇÃO A DISTÂNCIA VIA INTERNET

O desafio em educar adequadamente para a sociedade que se descortina hoje é muito grande. A percepção de crise se estabelece à medida que experimentamos uma situação de insatisfação permanente entre uma situação vivida e um padrão de resposta que já não atende a essa situação e essa crise torna-se benéfica quando nos obriga a uma introspecção da qual resulta uma revisão interior e a adoção de novos comportamentos.

Repensar nosso papel é nos situar como apenas uma fonte de informação, entre muitas outras, e em diferentes níveis de valor para nossos alunos, e que para não nos posicionarmos como ultrapassados, anacrônicos, precisamos urgentemente nos recontextualizar em nossa identidade e responsabilidades profisssionais (ALARCÃO, 2006, p.32). Para a Educação em Ciências, isso significa ir à busca de ferramentas que nos habilitem como professores de Ciências, a atuar com competência e autonomia em vistas de articularmos o tripé ciência, tecnologia e sociedade na construção e organização de conhecimentos pertinentes para o desenvolvimento coletivo de uma cidadania crítica e participativa.

Nesse processo, insere-se a necessidade de este profissional englobar na sua prática o uso da informática, da linguagem digital e das tecnologias de informação e comunicação da internet, como mais um canal de comunicação, busca de conhecimento e autoformação por meio da constituição de comunidades aprendentes, do exercício do trabalho em equipe, do partilhar de experiências, do solucionar de conflitos, do redirecionar de ações pedagógicas, do domínio de diferentes formas de acesso às informações, de como criticá-las, reuni-las, organizá-las, selecioná-las e avaliá-las na construção e reconstrução do cotidiano de sua prática como ator e autor da própria prática.

Nesse sentido, urge então pensar nas ações que possam superar os desafios da formação, do desenvolvimento e de valorização dos professores. Essas ações se configuram em um movimento já desencadeado no Brasil, e que visa à Formação Continuada de Professores de Ciências na perspectiva de que não há ensino de qualidade, nem reforma educativa, nem inovação pedagógica, sem uma adequada formação de professores (NÓVOA, 1995, p. 9).

Como ação possível a esses anseios surge a Educação a Distância via internet, objetivando proporcionar a constituição de uma via de comunicação permanente entre professores e formadores, que possibilite, mais que formação, também a interação, a cooperação e o compartilhamento de saberes e experiências.

Nessa perspectiva, cito Marco Silva (2003) para conceituar a educação a distância via internet como

[...] conjunto imbricado de técnicas, práticas, atitudes, modos de pensamento e valores que se desenvolvem juntamente com o crescimento do ciberespaço, isto é: do novo ambiente comunicacional que surge com a interconexão mundial de computadores e das memórias dos computadores; principal suporte de trocas e de memória da humanidade a partir do início do século XXI; novo espaço de comunicação, de sociabilidade, de organização, de informação, de conhecimento e, claro, de educação (p. 11).

Nessa apresentação, fica implícito o conceito de interatividade, fator que para os professores constitui um desafio importante, pois exige interligar nossa própria perspectiva à do sujeito aprendiz e a da sociedade na qual estamos inseridos.

A partir desse entendimento, acreditamos que a Educação a distância via internet, como modalidade que permite a superação dos limites de tempo e espaço e o acesso livre a 
diferentes fontes de informação, é modalidade coerente com o objetivo da construção cidadã do conhecimento que estamos perseguindo. Nesse sentido, mostra-se adequada ao desenvolvimento de cursos de formação de professores de ciências, pois, além de promover formação, habilita-os ao uso das tecnologias de informação e comunicação da internet, potencializando o educar com base no diálogo, troca, participação, intervenção, autoria e colaboração para um efetivo desenvolvimento da autonomia entre os atores envolvidos no processo educacional.

\section{A PESQUISA}

Encontramos na Pesquisa Narrativa, como procedimento alocado em uma matriz de investigação qualitativa que está baseada na experiência vivida e nas qualidades da vida e da educação (CONNELY \& CLANDININ, 1995), a forma de desenvolver esse processo de construção de conhecimento. Escolha metodológica que surge como adequada aos objetivos hoje de educar e fazer ciência, pelo fato de ter como princípio, criar compreensão e consequentemente novos sentidos (ZELLER in MCEWAN E EGAN, 1995, p.295).

Identificando os elementos que dão suporte à metodologia da pesquisa, a partir de ambientes de Cursos a Distância Via Internet, usados como objetos dessa investigação, envolvemos grupos de professores de Ciências como sujeitos dessa pesquisa.

Esses cursos foram: 1) O curso TECNOLOGIAS DE INFORMAÇÃO E COMUNICAÇÃO NA FORMAÇÃO DE PROFESSORES DE CIÊNCIAS, com o objetivo de contribuir para a formação continuada de professores de Ciências no que diz respeito à utilização pedagógica dos recursos das TICs no desenvolvimento de projetos para o ensino de Ciências. Foi planejado para ser desenvolvido com uma carga horária mínima presencial de 4 horas, destinadas à ambientação e apresentação do tema "As TICs e o ensino de Ciências", e de 16 horas a distância contando com apoio de material didático em hipertexto disponibilizado no ambiente virtual do eProinfo.

2) O curso AUTORIA DE MATERIAL IMPRESSO PARA EDUCAÇÃO A DISTÂNCIA, com o objetivo de orientar a padronização dos módulos do Programa EDUCIMAT, no que diz respeito à sua estrutura, linguagem, atividades, recomendações e requisitos básicos para a produção de material para EAD. Foi planejado com uma carga horária de $20 \mathrm{~h}$, com 4h presenciais para ambientação e habilitação ao uso do eProinfo, ambiente virtual do MEC, e 16h para desenvolvimento do curso a distância, com material didático dividido em 4 temas e atividades, disponibilizados um a cada semana, na ferramenta módulo do eproinfo. Esse curso teve 27 professores inscritos, destes, detive-me nos 13 docentes da carreira do magistério superior e da área de Ciências.

Como espaço de intervenção, aproveitamos a oportunidade em participar dos programas vinculados ao Núcleo de Pesquisa e Desenvolvimento da Educação Matemática e Científica - NPADC da Universidade Federal do Pará - UFPA. Esse Núcleo é unidade acadêmica de integração na produção de conhecimentos e em ações de formação continuada de professores de Ciências e Matemática, em todos os níveis de ensino, inclusive no de pósgraduação lato e stricto sensu.

Utilizamos como instrumentos de coleta de dados, ferramentas de comunicação e informação disponíveis no ambiente virtual de aprendizagem - eProinfo. Entre essas ferramentas, selecionamos a ficha de perfil (obrigatória para cadastro no ambiente) para registro do memorial de formação, o fórum de discussão para acompanhamento das discussões sobre os temas, e a Biblioteca para receber as produções escritas (atividades) dos participantes. 
No caso dessa pesquisa, elegemos como estratégia de interpretação dos dados, a análise das narrativas coletadas, a fim de encontrar uma forma de acesso ao conhecimento implícito do grupo pesquisado, explicitá-lo e defini-lo teoricamente.

\title{
OS RESULTADOS
}

O Curso de "Tecnologias de Informação e Comunicação na Formação de Professores de Ciências" - Grupo I - teve um número extremamente reduzido de professores de Ciências inscritos, apenas quatro. Esses poucos professores com acesso à internet em casa e/ou na Escola em que trabalham, atuam profissionalmente há pelo menos 10 anos. Esses sujeitos não conseguiram desenvolver comunicação a distância.

Segundo os dados colhidos na ferramenta estatística do eProinfo, observamos o registro de em média 5 acessos ao ambiente do curso por esses professores. Porém, nessas incursões, apenas um deles conseguiu entrar no fórum, no entanto, sem esboçar participação.

Esse comportamento revela que no caso dos professores de Ciências, é necessário habilitá-los ao uso das TICs na educação, como forma de promover sua formação continuada por meio da modalidade da EAD via internet. Desenvolver essas habilidades tem muita importância nessa modalidade, uma vez que

\begin{abstract}
No curso a distância, a comunicação se fez por escrito e a interação com o computador e com o outro, por meio do editor de textos nas diversas ferramentas: Grupo de Discussão, Perfil, email (sic), etc. É importante salientar que a escrita estava em todas as situações, e nela também, potencialmente, as possibilidades pedagógicas de aprendizagem e transformação do professor-aluno (KACHAR, 2003, p. 91).
\end{abstract}

A falta de habilidade dos professores com as ferramentas de informação e comunicação da internet, como elemento que dificulta o andamento do curso, revelou-se como fator preponderante na análise dos resultados dessa pesquisa.

Esses resultados nos encaminham para a indicação de recursos humanos preparados para dar suporte de atendimento e acompanhamento de alunos a distância via internet com o objetivo de desenvolver nesses alunos não só habilidades com o uso das TICs, assim como lhes permitir criar vínculos, ou seja, promover uma relação mais próxima com o professortutor e seus colegas.

Diante do que nos afirma Paz (2003, p. 335), a presença de monitores, objetivando alcançar com mais facilidade o desenvolvimento de uma cultura da educação sem distâncias, é fundamental. Esses atores, além de atenderem a alunos e professores com as dificuldades com a habilitação ao uso das tecnologias, também favorecem a criação de um ambiente de afetividade e de segurança, importantes no vencer o desafio do desconhecido.

O Curso de "Autoria de Material Impresso para EAD" - Grupo II, destinado a professores formadores, foi constituído por treze docentes, sendo 8 mestres e 5 doutores. $\mathrm{O}$ objetivo do curso era a produção de material didático para as ações de formação de tutores e de professores do Programa EDUCIMAT. Esses professores pertencem ao quadro das Universidades do Estado do Pará, atuando nos cursos de Licenciatura e/ou nos cursos de formação continuada de professores (aperfeiçoamento, especialização, mestrado e doutorado).

De áreas diversificadas das Ciências, apesar de afirmarem ausência de problemas em relação ao acesso à internet, demonstraram dificuldades em interagir e construir conhecimento a distância. Embora voltados para o trabalho acadêmico e a formação de professores, este grupo não avançou no que diz respeito à interação cooperativa, nos termos de Kachar (2003, p.95), ou seja, “[...] em se tornar co-responsável pela própria aprendizagem e a do colega". 
Nos temas abertos no fórum do ambiente virtual, deixaram transparecer suas dúvidas sobre a validade da Educação a Distância. Essa dúvida se exemplifica na interação de um formador:

A modalidade da educação a distância é uma forma de contribuir para aumentar o número de pessoas capacitadas, mas como saberemos que nossos objetivos serão alcançados, se em um curso presencial isso já é difícil? (Formador 13).

Além disso, percebemos que existe entre eles o entendimento de que a modalidade é uma forma de atender quantitativamente às necessidades de formação da nossa região, porém revela-se a dificuldade em pensar em uma avaliação a distância. A questão da avaliação em EAD é um fator que "assombra" muitos formadores. É o elemento que provoca maior dúvida em relação à validade dessa modalidade educacional. De acordo com Azevedo (2005, p. 5),

[...] a grande preocupação com a validação dos programas em EAD é em decorrência das dificuldades com a avaliação, no sentido de desconfiar no desenvolvimento do processo de aprendizagem a distância, preconceito construído historicamente pelo caráter de suplência com que essa modalidade foi usada e que a rotula como modalidade de baixa qualidade.

Entendemos que a dúvida perpassa pelo desconhecimento da metodologia recomendada para a EAD via internet, denominada por Valente (2003) como "o estar junto virtual", em que há o acompanhamento constante do aluno propondo um rompimento com a distância e com a natural comparação entre a modalidade presencial e a distância. $\mathrm{O}$ estar junto virtual prioriza

[...] aprender mais sobre os alunos, sobre si mesmo e o mundo, quando tem competência para escutar os alunos. Apesar da distância podemos dar atenção ao outro, trocar afetos; a maior distância é a que se faz na presença ausente (KACHAR, 2003, p. 95).

Vemos aqui que ao professor ou o tutor é recomendado o compromisso de conhecer o perfil desse aluno, seus anseios, virtudes, necessidades e limitações para que esses fatores se mantenham e garantam o sucesso da aprendizagem, objetivo de todos. Alguns formadores demonstraram a importância desse compromisso como no exemplo apresentado a seguir:

A EAD além de diminuir a distância é uma forma de capacitar as pessoas. E, por ser "uma forma" tem características próprias. Uma dessas características é a interação. Isso me preocupa!!! Penso que a interação não é algo somente físico (Formador 3).

$\mathrm{Na}$ interpretação do que nos mostra as interações do grupo de formadores, mesmo que todos estivessem envolvidos com a produção de material para cursos de formação continuada de professores de ciências, o que se revela como fator preponderante é a dificuldade em reconhecer uma metodologia que dê credibilidade à Educação a Distância, principalmente no que se refere ao processo de avaliação. Essa análise nos encaminha para a ideia de que, antes de investir pesado em tecnologias de hardwares e softwares, o que é mais importante hoje é investir em preparação e formação de pessoal para a EaD via internet.

\section{CONSIDERAÇÕES FINAIS}

O que os resultados da pesquisa nos mostram é que a ineficiência não está na falta de computadores ou de infra-estrutura adequada, mas sim na falta de hábito ao se apropriar da rotina recomendada para a metodologia via internet, além da existência de uma sutil 
desconfiança na qualidade da modalidade, principalmente no que diz respeito ao processo de avaliação da aprendizagem.

Nesse sentido, cuidar de elementos como a gestão de pessoal e os recursos pedagógicos e administrativos, considerando nossas peculiaridades regionais e culturais, o perfil do público alvo e infra-estrutura disponível, é de suma importância no indicar de ações adequadas à formação de professores de Ciências no Estado do Pará.

Apesar de já estarmos pensando em tendências e novas perspectivas em relação à veloz evolução da Educação a Distância articuladas ao uso das TICs, pesquisas nessa área ainda têm status de inovação, de novidade. No que diz respeito à Educação em Ciências, vislumbramos como trabalhos futuros, a construção de um Portal integrando os professores de ciências em uma grande comunidade em rede, assim como a Constituição de Laboratórios Virtuais para a experimentação científica (construção de ambientes simulados inteligentes).

\section{REFERÊNCIAS}

ALARCÃO, I. Professores Reflexivos em uma Escola Reflexiva. 2 Ed. São Paulo: Cortez, 2006.

CONNELLY, F. M,; CLANDININ D.J. Relatos de Experiencia e Investigación Narrrativa. In: LARROSA, J. et al. Déjame que te cuente: ensayos sobrenarrativa y educación. Barcelona: Editorial Alertes, 1995.

KACHAR, V. (2003). Realização de Projetos Baseados em Texto. In: VALENTE, A (org). Educação a Distância Via Internet. São Paulo: Avercamp, 2003.

NÓVOA, A. Formação de professores e profissão docente. In: NÓVOA, A. (Org.). Os professores e sua formação. Portugal: Dom Quixote, 1995.

SILVA, M. Educação online: teorias, práticas, legislação e formação corporativa. Edições Loyola, São Paulo, 2003.

VALENTE, A (org). Educação a Distância Via Internet. São Paulo: Avercamp, 2003. 